\title{
Colonoscopy in Management of Colonic Strictures
}

\author{
RICHARD H. HUNT, ROBIN H. TEAGUE, EDWIN T. SWARBRICK, CHRISTOPHER B. WILLIAMS
}

British Medical fournal, 1975, 3, 360-361

\section{Summary}

A total of 160 strictures were examined in 154 patients with the fibreoptic colonoscope. When it was possible to make a pre-examination diagnosis colonoscopy proved it wrong in $\mathbf{5 2} \%$ of cases. Unnecessary laparotomy was probably avoided in over half this series. All strictures of the large bowel should be examined colonoscopically whenever possible before considering surgery.

\section{Introduction}

Localized strictures of the large bowel present considerable diagnostic difficulties for both clinician and radiologist and in many cases the diagnosis is established only at laparotomy. Fibreoptic colonoscopy is a relatively simple and safe method of examining all the large bowel and is an invaluable diagnostic and therapeutic technique. ${ }^{12}$

We report here our experiences of colonoscopy in patients in whom a stricture was shown radiologically by barium enema.

\section{Patients and Methods}

A total of 154 patients with 160 strictures were examined. All patients had had a barium enema, and in over $80 \%$ double contrast barium enemas had been performed.

Instruments.-The instruments used were the A.C.M.I. 9000 P.L. and F.9.A, Olympus C.F.S.B., C.F.M.B. and C.F.L.B., and Machida F.S.S. colonoscopes. Routine A.C.M.I. F.C.B. 1000 and Olympus C.L.E. and C.L.S. light sources were used.

Preparation of Patient.-Most patients were examined as outpatients. All were prepared with a high intake of oral fluids, a low residue diet, and purgation with castor oil or sennosides. Most patients known to have active inflammatory bowel disease received magnesium sulphate or citrate rather than the stronger cathartics. One or two hours before the examination the patient received either two enemas containing oxyphenisatin (Veripaque) $1 \mathrm{~g} / 1$ or two high colonic washouts with five litres of tapwater.

Medication.-Sedation was usually achieved with intravenous pethidine and diazepam though some patients undergoing limited left-sided examinations had no sedation. Hyoscine butylbromide (Buscopan) was used in some patients, especially in those with diverticular disease or muscle spasm.

Techniques.-Colonoscopic examination was performed on an $x$-ray table with image intensifying facilities. We have reported our endoscopic techniques elsewhere, ${ }^{2}$ but in examining strictures a particular difficulty occurs when the tip of the colonoscope becomes lodged within, or acutely angled at, a stricture and it may be impossible to take biopsy specimens while maintaining good visualization of the lesion. The instrument therefore has to be withdrawn slightly to enable the forceps to pass through the flexible tip and open satisfactorily. In two cases it was not possible to obtain specimens. Specimens were obtained for cytological examination using both brushings and washings. All polyps encountered during the examinations were removed or destroyed using diathermy techniques. ${ }^{3}$

\section{St. Mark's Hospital, London EC1V $2 P S$}

RICHARD H. HUNT, M.B., M.R.C.P., R.N., Honorary Research Fellow EDWIN T. SWARBRICK, M.B., M.R.C.P., Research Fellow

CHRISTOPHER B. WILLIAMS, M.B., M.R.C.P., Consultant Physician

Department of Medicine, Royal Infirmary, Bristol

ROBIN H. TEAGUE, M.B., M.R.C.P., Senior House Officer

\section{Results}

The 160 strictures examined were distributed in the colon as shown in the fig. It was possible to pass through the strictures in 106 patients, but in 38 patients only the distal part of the stricture could be examined. In 10 patients it was impossible to reach the stricture and the examination was classified as a failure, though two of the 10 were successfully re-examined. There was no mortality or morbidity in this series. For analysis the patients were divided into the five groups described below according to the clinical and radiological diagnoses made before the examination.

Clinically Malignant Strictures.-Fifty-three patients were thought to have malignant strictures. In 18 cases the endoscopic appearances of malignancy were confirmed histologically, and another four patients in whom the diagnosis was made on visual grounds alone were shown to have carcinomas at laparotomy. One further patient was abnormal on examination but the appearances were not diagnostic. The biopsy specimens were non-contributory and the patient was shown at laparotomy to have a carcinoma in the strictured area. No further cases of "missed" carcinomas have appeared in the follow-up period of 16 months to three and a half years. Fourteen patients were entirely normal on examination and four others showed persistent but benign spasm in the apparently strictured area. Benign polyps were found in five patients, ulcerative colitis in two, Crohn's disease in one, diverticular disease in one, and ischaemic stricture in one. The examination failed in three patients.

Diverticular Disease Associated with Possible Malignancy, Crohn's Disease or Polyps. - Of the 39 patients examined 14 were thought to have malignancy within the strictured area but this was confirmed endoscopically and on biopsy in only four. Twelve patients were diagnosed as having possible polyps in the strictures and this was confirmed in eight. Two of these polyps were malignant but there was no carcinomatous invasion of the stalk and the patients were managed by local excision alone. Previously unsuspected polyps were found in two of these patients. Of the 13 patients thought to have Crohn's disease in association with diverticular disease the diagnosis was confirmed in only one, but the examination failed in three.

Strictures in Ulcerative Colitis.-Twenty-eight strictures were examined in 24 patients who had suffered from ulcerative colitis for at least eight years. Malignancy was found in only three of the patients; and premalignant changes were found throughout the colon in one case, throughout the colon except the rectum in another case, and in the rectum alone in the third case. Apart from one patient with an ischaemic stricture all the others had muscular strictures.

Strictures in Crohn's Disease. - In nine of the 12 patients examined the radiological and clinical diagnosis was confirmed on direct vision.

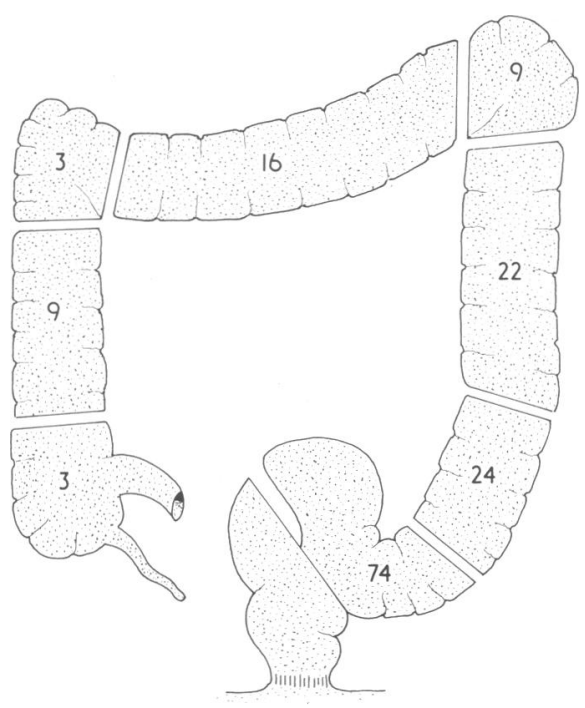

Site of 160 strictures of colon examined with colonoscope. 
The appearances were typical of Crohn's disease with discrete aphthoid or serpiginous ulcers with normal intervening mucosa. Only one patient showed the characteristic histological features, ${ }^{4}$ and a further six showed non-specific inflammatory changes.

Others.-This group comprised 26 patients who had strictures shown radiologically but who did not fall into any of the other categories. Eight patients were normal endoscopically, seven had muscle spasm only, two had carcinomas, three had benign adenomatous polyps in association with spasm, two had Crohn's disease and two had diverticular disease. Examinations failed in two patients.

\section{Discussion}

Strictures are often found that do not show radiological characteristics typical of one condition even though double contrast studies may provide helpful additional information and may indicate or exclude disease elsewhere in the large bowel. We have shown that colonoscopy provides a safe, reliable, and effective way of elucidating the differential diagnosis of strictures of the large bowel.

Of the 160 strictures examined 96 were in the signmoid colon but beyond the reach of the conventional rigid sigmoidoscope. This is a notoriously difficult area to examine radiologically and similarly has proved to be a difficult region to negotiate with the colonoscope, particularly in the presence of diverticular disease. One group of workers reportęd a $47 \%$ failure rate in the study of the differential diagnosis of carcinoma from diverticular disease. ${ }^{5}$ Our failure rate in this group was $8 \%$ and we believe that the difference may be due partly to the routine use of fluoroscopy and partly to slow and painstaking endoscopic technique in these patients.

Altogether $90 \%$ of the strictures examined were within reach of the medium length $(105-110 \mathrm{~cm})$ instruments, which are easier to handle, more durable, and less expensive to repair or replace; they should be used where possible. The two-channel "operating" colonoscope has, surprisingly, proved particularly easy to use in spite of its diameter.

If patients with longstanding ulcerative colitis develop strictures the colon is usually removed because it has until now been impossible to distinguish between malignant and benign strictures. With diagnostic colonoscopy surgery may be avoided in some patients. It is becoming apparent that the precancerous epithelial dysplasia (atypia) associated with the development of a carcinoma in longstanding ulcerative colitis $^{6}$ may be patchy and may spare the rectum, as in one of our cases. ${ }^{7}$ Nevertheless, it is almost invariably present in the mucosa immediately surrounding a carcinoma, ${ }^{8}$ and it is therefore imperative to take multiple biopsy specimens from any strictured area in patients with ulcerative colitis. Provided there is no evidence of epithelial dysplasia in these biopsies the stricture is almost certainly benign.

During colonoscopy it is difficult to make an accurate diagnosis on direct vision alone and biopsy specimens are essential. Malignant polyps often look benign, benign polyps malignant, and inflamed mucosa normal. ${ }^{9}$ In certain conditions, however, the converse may be true. In eight of our nine patients examined for Crohn's disease the biopsy specimens showed only nonspecific inflammatory changes in spite of the typical macroscopic appearance. This probably reflected the small, relatively superficial specimens which were obtained. We have found that the results of cytological and histological examinations of biopsy material correlate well and believe that taking biopsy specimens by brushing and washing is valuable in the colonoscopic diagnosis of strictures, particularly those through which it is impossible to pass the instrumeni.

The diagnosis was proved wrong in $52 \%$ of the 104 cases in which the clinicians and radiologists were prepared to make a probable diagnosis. In the remaining 50 patients a positive diagnosis was made on colonoscopy in all except two. Laparotomy was probably avoided in over half of this series as a direct result of colonoscopy, and though we have failed in 5\% of our patients this failure rate is small compared with the obvious clinical and economic benefits of the whole series.

\author{
References \\ 1 Woolf, W. I., Shinya, H., and Ozoktay, S. Z., American Fournal of Surgery, \\ $1972,123,180$ \\ 2 Williams, C. B., and Teague, R., Gut, 1973, 14, 990. \\ 3 Williams, C. B., et al., British fournal of Surgery, 1974, 61, 673. \\ ${ }^{4}$ Lockhart-Mummery, H. E., and Morson, B. C., Gut, 1964, 5, 493. \\ 5 Dean, A. C., and Newell, J. P., British fournal of Surgery, 1973, 60, 633. \\ ${ }^{6}$ Morson, B. C., and Pang, L. S. C., Gut, 1967, 8, 423. \\ 7 Evans, D. J., and Pollock, D. J., Gut, 1972, 13, 566. \\ ${ }^{8}$ Morson, B. C., personal communication, 1975. \\ ${ }^{9}$ Dilawari, J. B., et al., Gut, 1973, 14, 426.
}

\title{
Aspects of Sexual Medicine
}

\section{An Approach to the Gynaecological Patient}

\author{
PHILIP RHODES
}

British Medical fournal, 1975, 3, 361-363

\section{Privacy}

Doctors in general have often been upbraided for not having much insight or understanding of sexual disorders, and perhaps this criticism should be accepted. But it is not surprising that

Faculty of Medicine, University of Adelaide, Australia PHILIP RHODES, F.R.C.S., F.R.C.o.G., Dean there may have been reticence on the part of the medical profession, because there has not until recently been a reasonably received body of knowledge on sexual matters, nor was there suitable, convincing, and tested treatment for many of the sexual disorders. This is still largely true, though recently genuine attempts have been made to define and put on a scientific basis the diagnosis and management of sexual problems. It may be true that the doctors have been conservative, but they have been a useful brake on enthusiastic amateurs, of whom there are many in the sexual sphere, whose pet nostrums and theories have not had the all-embracing application that they fondly imagined. Sexual problems are very individual, affecting the 